\title{
CASAS, RUAS E VÍRUS: POSSÍVEIS TENDÊNCIAS DO DIREITO DO TRABALHO NA ERA PÓS PANDEMIA
}

\author{
HOME, STREETS AND CORONAVIRUS: A POST-PANDEMIC LOOK AT LABOUR LAW
}

\section{Maria Rosaria Barbato}

Doutora em Direito pela Università di Roma Tor Vergata com período sanduíche na UFMG. Professora Adjunta IV da Faculdade de Direito da Universidade Federal de Minas Gerais (UFMG), vinculada ao Programa de Pós-graduação em Direito da UFMG.

E-mail: mr_barbato@hotmail.it

\section{Marcio Túlio Viana}

Pós-doutor pela Università di Roma Tor Vergata e Università di Roma I la Sapienza. Professor Associado (Aposentado) da UFMG, Professor Adjunto IV da Pontifícia Universidade Católica de Minas Gerais (PUC/MG), vinculado ao programa de Pós-Graduação em Direito da PUC/MG. E-mail: tgviana1@gmail.com

Recebido em: 08/08/2020

Aprovado em: 05/11/2020

RESUMO: Até algumas décadas atrás, tanto o sindicato quanto o Direito do Trabalho poderiam ser representados, metaforicamente, por uma casa - com os seus atributos de solidez, permanência, segurança, previsibilidade. Hoje, ambos parecem caminhar para o modelo rua - com as suas marcas de insegurança, surpresa, instabilidade. Este pequeno artigo trabalha essa hipótese, buscando mostrar como a transformação do contexto exterior vem se refletindo na produção e na aplicação das normas jurídicas trabalhistas e quais os riscos e as possibilidades que o futuro nos reserva. Traça não apenas uma visão panorâmica das tendências do Direito do Trabalho - do passado ao futuro - como sugere possíveis soluções para a crise que o vem afetando e o afetará ainda, de forma provavelmente mais grave, no período pós pandemia. Com abordagem multidisciplinar, e recorrendo especialmente a obras de doutrina, a pesquisa conclui pela pertinência da hipótese, traçando linhas genéricas para que o Direito do Trabalho retome a sua tradição de diminuir as desigualdades sociais produzidas pelo sistema capitalista.

Palavras-chave: Direito do Trabalho. Sindicato. Precarização. Flexibilização. Pandemia.

\begin{abstract}
Up until recently, both the figures of the Union and of Labour Law could have been represented by a house - a home - with its core values of sturdiness, permanence, security and predictability. In the past few decades, both have undergone a shift and are now more closely represented by the figure of the street, with its core characteristics of insecurity, surprise and a lack of stability. This brief article covers the concept of transformation, hypothesizing what the future may have in store for Brazil's Labour Law, particularly in the period following the Covid-19 pandemic. With a multidisciplinary approach, and a particular focus on doctrinal works, the
\end{abstract}


research brings forward supporting arguments for the hypothesis.

Keywords: Labour Law. Unión. Precariousness. Destabilization. Pandemie.

SUMÁRIO: Introdução. $1 \mathrm{O}$ panorama de ontem. 2 O panorama de hoje e as possibilidades do amanhã. 2.1 A rua como novo personagem. 2.2 O novo personagem da rua. 2.3 Rua e direito. Conclusões. Referências.

\section{INTRODUÇÃO}

Como não é segredo para ninguém, tudo interage com tudo. Em Roma, nas tempestades de verão, os ventos às vezes trazem areias do Saara; com o aquecimento global, é possível que se libertem novos e perigosos vírus, até hoje adormecidos sob as camadas de gelo ${ }^{1}$.

Na Amazônia, as chuvas quase diárias não se originam apenas da evaporação dos rios; as árvores transpiram compostos orgânicos, que aglutinam as moléculas de água, e esses compostos, exalando leves perfumes, fortalecem o sistema imunológico de quem caminha pela floresta ${ }^{2}$.

No campo das relações sociais, as interações também se multiplicam. Uma pequena mudança num artigo de lei pode afetar a interpretação de outras tantas normas; conforme o caso, pode até mesmo despertar no juiz reações que também pareciam adormecidas, como se ao seu redor derretesse uma camada de gelo.

Com mais razão, se grande parte da sociedade passa a viver emoções diferentes, e a atribuir novos sentidos para o mundo, a vida do Direito se transforma - ainda que as estruturas, aqui ou ali, conservem a mesma aparência.

O que o texto propõe é exatamente mostrar as tendências que hoje presidem essas interações. São ideias simples, sujeitas a crítica, mesmo porque, como também sabemos, infinitas variáveis transitam pelas nossas vidas; o acaso é um elemento presente não apenas no reino da Biologia quanto em nosso cotidiano ${ }^{3}$.

Substancialmente, e valendo-se de duas metáforas - a casa e a rua - a pesquisa trabalha com a hipótese de estarmos vivendo uma profunda transformação nas tendências históricas do Direito do Trabalho, com reflexos em suas fontes e em seu conteúdo - processo que tende a ser acelerado em razão da atual pandemia. Para confirmar essa hipótese, opta pela investigação multidisciplinar, abrangendo aspectos do Direito, da História, da Antropologia e outras ciências afins, e fundada especialmente em pesquisa bibliográfica.

O objetivo básico é tentar desnudar - ou pelo menos aclarar um pouco -o curso de um processo que tem permanecido nas sombras, a fim de possibilitar uma crítica mais profunda do processo de desconstrução do Direito do Trabalho e abrir novos caminhos para a sua reversão.

\section{O PANORAMA DE ONTEM}

A palavra "lar" é tão curta quanto rica. Ela nos remete, por exemplo, ao lugar onde vivemos, junto às pessoas que nos são mais próximas e queridas ${ }^{4}$; ao deus que os antigos cultuavam, e que protegia a família, na forma de um fogo; à ideia de um recanto nosso, e de mais ninguém, e onde os estranhos só entram se autorizados por nós.

\footnotetext{
${ }^{1}$ FOX-SKELLY, Jasmin. There are diseases hidden in ice, and they are waking up. BBC, 04 may 2017. Disponível em: http://www.bbc.com/earth/story/20170504-there-are-diseases-hidden-in-ice-and-they-are-waking-up. Acesso em 20/09/2020.

${ }^{2}$ VIANA, Virgílio Mauricio, professor convidado em Harvard. Palestra no Programa de Pós-graduação em Direito na PUC-Minas. Belo Horizonte, 18/03/19.

${ }^{3}$ MONOD, Jacques. O acaso e a necessidade. Petrópolis: Vozes, 1976, p. 137.

${ }^{4}$ COULANGES, Fustel de. A cidade antiga. São Paulo: Editora das Américas, 2006, p. 14.
}

Revista de Direito Brasileira | Florianópolis, SC | v. 26 | n. 10 | p. 311-324 | Mai./Ago. 2020 
Durante milhares de anos nos habituamos a ver o lar - em sua expressão material - na forma de uma construção de tijolos, com as suas paredes, o seu teto e o seu chão, assim como as suas portas e janelas. Sob os aspectos real e metafórico, esta construção - a casa - transmitia a ideia não só de solidez e permanência, mas de defesa e proteção.

Com a modernidade, especialmente, o lar (ou a casa) passou também a simbolizar, em certo sentido, a nossa relação com o espaço e o tempo, um e outro bem separados, bem definidos à semelhança de seus quartos, salas e banheiros - e por sua vez definindo os nossos próprios passos ao longo dos dias e da vida.

Apenas as portas - e, em menor medida, as janelas - mantinham certa ambiguidade, pois tanto podiam nos abrigar e conter, quando fechadas, como nos soltar para o mundo, quando as abríamos para a rua. Eram como uma espécie de pele - tênue espaço entre o dentro e o fora.

Da mesma forma que o lar, a fábrica continha elementos de abrigo e de permanência. E era também um lugar que dava ao trabalhador a sensação de que ele era um cidadão, um sujeito de direitos, ainda que nem sempre, na prática, fosse bem assim.

$\mathrm{Na}$ verdade, os próprios direitos - como o salário base, as horas extras, as indenizações pareciam estar ali, contidos naquelas quatro paredes. Afinal, eles legitimavam e também limitavam a opressão do dia a dia; e a pessoa que os devia pagar, de certo modo, morava ali.

Naquela espécie de casa, pode-se dizer até que o trabalhador reencontrava, em seu inconsciente, as figuras da mãe ou do pai, tanto em forma de proteção quanto de disciplina, como nos mostram algumas pesquisas ${ }^{5}$. Proteção, quando a fábrica o ajustava à moral social, que lhe exigia trabalho, e deste modo o salvava da crítica social ou mesmo das rondas da polícia; disciplina, ao ajustá-lo à linha de montagem, girando manivelas ou apertando parafusos, em troca de um salário que lhe permitia, às vezes, até se esquecer do que fazia ${ }^{6}$.

Também naquela espécie de casa, entre um parafuso e outro, o trabalhador podia ir arquitetando os seus pequenos planos, como a pescaria do fim de semana ou - com um pouco de sorte - as férias com a família, talvez à beira do mar. Na hora do almoço, podia também contar anedotas, brincar com os amigos, trocar confidências ou falar de futebol, vivendo então os seus minutos de gente.

Às vezes, podia até inventar certas manhas para facilitar o trabalho, pois nem mesmo o modelo taylorista de produção tinha sido capaz de eliminar completamente os seus saberes tácitos ${ }^{7}$. Nos momentos de mais rebeldia, podia também praticar outras formas de resistência, rabiscando o banheiro contra o patrão, fazendo corpo mole quando a ocasião permitia ou cochichando notícias sobre a próxima greve.

Por seu turno, e à semelhança do lar e da fábrica, o sindicato se erguia sobre alicerces duros, de bom concreto, e também continha, moldava e protegia o operário entre as suas quatro paredes. E se o lar tinha o seu deus, nas pessoas dos mortos, e a fábrica também o tinha, na figura de seu fundador, no sindicato este deus era o grande líder, capaz de dizer às coisas que todos queriam ouvir, e de propor as palavras de ordem, as táticas da greve, os termos da negociação.

O próprio Direito do Trabalho, de certa maneira, foi erguido como a fábrica, o lar e o sindicato, apresentando as mesmas virtudes de certeza, proteção, controle e durabilidade. Os seus princípios eram as suas paredes. E se as portas e janelas permitiam, às vezes, a entrada de algum elemento estranho era preciso que ele antes batesse à porta, pedindo licença, e se mostrasse compatível com o interior da casa - como dispunha, expressamente, o art. $8^{\circ}$ da CLT.

\footnotetext{
${ }^{5}$ Cf. LIMA, Maria Elizabeth Antunes. Os equívocos da excelência. Petrópolis: Vozes, 1996.

${ }^{6}$ Veja-se, sobre este último aspecto, o testemunho de WEIL, Simone. A condição operária e outros estudos sobre a opressão. Rio de Janeiro: Paz e Terra, 1996.

${ }^{7}$ Cf. DOS SANTOS, Geraldo Alves dos. A pedagogia da ferramenta: estratégias de produção e formalização de saberes tácitos criados pelos ferramenteiros de uma indústria metalúrgica (dissertação de mestrado). Belo Horizonte: UFMG, 2004.
} 
Também como a fábrica, o lar e o sindicato, as normas de proteção fortaleciam ainda mais os laços entre os operários, não só porque eram, com frequência, a prova viva de suas lutas, como também porque lhes prometiam um destino comum.

Além disso, se o Direito do Trabalho dividia, parcelava, por outro lado também recompunha, mimetizando nesses dois movimentos a linha de montagem e as hierarquias sindicais. O seu padrão era o contrato sem prazo, quase sempre duradouro, previsível, sem surpresas legislativas no caminho - exceto as que o fortaleciam e ampliavam.

Sempre como a fábrica e o sindicato, o Direito perseguia uma linha reta, coerente. E os seus princípios - assim como os alicerces de uma casa - também serviam para isso. Mesmo a sua vocação de avançar sem cessar, redistribuindo parte das riquezas - também crescentes - do capital tinha um componente de estabilidade, já que os avanços se davam, naturalmente, sempre na mesma direção ${ }^{8}$.

Na verdade, o próprio mundo era assim, bem mais simples, planejado e seguro, e, por isso, ainda otimista e confiante - apesar de suas profundas desigualdades, de seus desastres ecológicos e de duas guerras mundiais. Daí os grandes sonhos e projetos, e, também por esta razão, uma maior tolerância e respeito em relação às regras, disciplinas e hierarquias, teoricamente destinadas a realizá-los.

Num mundo como esse, a memória coletiva tinha especial importância. No interior do sindicato, assim como no lar ou na empresa, podiam-se encontrar mais facilmente recordações antigas - como falas, fotos, escritos ou algum outro objeto - que as pessoas ainda reverenciavam. Afinal, para realizar o futuro, era preciso valorizar o passado, reconstruído sob o olhar do presente.

Por tudo isso - e não obstante os desejos de autonomia, tão caros à modernidade- a liberdade convivia de forma menos conflitiva com o seu contrário, exceto, basicamente, entre os jovens e algumas outras minorias. Aliás, até na utopia revolucionária seriam exatamente os trabalhadores subordinados que fariam a revolução... Não à toa, os sindicatos ignoravam os autônomos, mesmo quando pobres e sofridos.

E hoje?

\section{O PANORAMA DE HOJE E AS POSSIBILIDADES DO AMANHÃ}

Hoje, o lar já não conserva com a mesma facilidade os seus valores tradicionais, as suas antigas hierarquias, sua aparente ou real estabilidade. Já não consegue sequer evitar que o trabalho de fora entre pela porta adentro. E também a fábrica e o sindicato. parecem deslizar sobre os seus próprios pés. Os alicerces balançam; as portas e as janelas, arrombadas, deixam entrar e sair os mais diferentes personagens; e a supressão literal do requisito da compatibilidade, na nova redação do art. $8^{\circ}$ da CLT, é apenas a tradução, no campo do Direito, dessa nova tendência, que também o atinge. ${ }^{9}$

Ao invés do uniforme, do previsível, do seguro, do estável, do contido e do regulado, vivemos tempos líquidos ${ }^{10}$, ou a emersão do múltiplo ${ }^{11}$, (VÁZQUEZ, 2011, passim). Tudo é fluido e variado - inclusive as verdades. Não à toa, em 2018, "pós verdade" foi eleita a "palavra do ano" pelos professores de Cambridge.

\footnotetext{
${ }^{8}$ LA CUEVA, Mario. El Nuevo Derecho Mexicano del Trabajo, tomo I. México: Porrua, 1956.

${ }^{9}$ A redação anterior dizia do parágrafo único do art. $8^{\circ}$ dizia: "O direito comum será fonte subsidiária do direito do trabalho, naquilo em que não for incompatível com os princípios fundamentais deste". A nova redação do parágrafo $1^{\circ}$ do mesmo artigo diz: "O direito comum será fonte subsidiária do direito do trabalho". Mas isso não significa, necessariamente, que devamos interpreta-lo como quis o legislador - já que sempre se pode entender que lei apenas suprimiu uma redundância e, de todo modo, a aplicação de um direito incompatível violaria os princípios do Direito do Trabalho.

${ }^{10}$ BAUMAN, Zigmundt. A modernidade líquida. São Paulo: Zahar, 2014.

${ }^{11}$ VAZQUEZ, Adolfo Sánchez. As ideias estéticas de Marx. Rio de Janeiro: Paz e Terra, 1968.
} Revista de Direito Brasileira | Florianópolis, SC | v. 26 | n. 10 | p. 311-324 | Mai./Ago. 2020 
Nesse contexto, as próprias regras de proteção parecem desprotegidas; e nem mesmo os princípios lhes servem de anteparo, já que eles próprios passam a ser lidos ao contrário. Com menos sonhos, projetos e utopias; e resistentes - também por isso -a tudo o que é organização, disciplina e hierarquia, os trabalhadores já não encontram no sindicato uma forma de se realizar como gente e como grupo, ou mesmo de suprir suas carências - até afetivas -, compensando as dores do trabalho.

Naturalmente, há muitos outros fatores que conspiram contra a união coletiva. Apenas como exemplos, podemos citar o enfraquecimento do Estado, o fortalecimento correspondente das grandes corporações, a ideologia, as terceirizações, o modelo de fábrica em rede, o uberismo, os contratos curtos, diferenciados e fragmentados, e, em geral, tudo o que compõe a chamada "reestruturação produtiva". Até a arquitetura tradicional do sindicato parece desafiar a mobilidade (muito maior) dos produtos, das ideias, das emoções e dos próprios projetos pessoais.

Para muitos trabalhadores, a CLT já não parece símbolo de sua resistência, enquanto classe, mas - ao contrário - uma ameaça ao seu emprego. Mesmo quando não é assim, as novas regras - menos coerentes, mais heterogêneas e fragmentárias - já não os enredam como antes, servindo, às vezes, até para dividi-los - como, por exemplo, ao fomentar a prática de prêmios.

Como se não bastasse, a perda crescente da memória coletiva- potencializada pela "hipertrofia do presente" 12 , mas também pela tendência ao recorte, ao fragmento - dificulta ainda mais a utilização do passado para a construção do futuro. E os novos modos de produzir potencializam, cada vez mais, esse processo, jogando com a tendência de autoafirmação do sujeito para transforma-lo numa espécie de clone do patrão ${ }^{13}$, sempre em busca de performances ${ }^{14}$ e em regime de competição.

Acima, falamos de alicerces que balançam. Mas a realidade parece ainda mais drástica. Se tudo entra e tudo sai, e se tudo se transforma muito mais, e em velocidade tão surpreendente, é porque o próprio modelo arquitetônico da casa está sendo engolido pelo seu oposto.

Das construções perenes e tranquilas - como eram o nosso lar, as sedes das empresas, os prédios dos sindicatos e a nossa CLT - passamos a priorizar o modelo da rua, com as suas esquinas, os seus cortes, as suas surpresas, as suas não razões, a sua inconstância, o seu movimento convulsivo e quase caótico.

\subsection{A rua como novo personagem}

Ao longo dos tempos, a rua tem sido palco de encontros e desencontros, lamentos e alegrias, amores e conflitos. Por isso mesmo, como se dizia, é o lugar do imprevisto, do inesperado, da surpresa.

Era nas ruas, por exemplo, que as mulheres inglesas - entre os séculos XVI e XIX, sobretudo -marchavam para preservar o preço do pão, às vezes comandando os seus maridos; era também pelas ruas que algumas delas, em outros dias, desfilavam com uma corda no pescoço, puxadas pelos mesmos maridos, que as vendiam na feira ${ }^{15}$.

Foi ainda nas ruas que as comunas de Paris construíram suas barricadas; que os estudantes e operários, no fim dos anos 60, tentaram exigir um novo modelo de mundo; que multidões, no Brasil, realizaram as primeiras greves gerais, protestaram contra a ditadura e defenderam as "diretas-já".

\footnotetext{
${ }^{12}$ NORONHA, Elaine Nassif. Conciliação judicial e indisponibilidade de direitos: paradoxos da "justiça menor" no processo civil e trabalhista. São Paulo: LTr, 2005.

${ }_{13}$ TEODORO, Maria Cecilia Máximo. A síndrome de patrão. Mgalhas, 4 de maio de 2017. Disponível em: https://www.migalhas.com.br/depeso/258217/a-sindrome-de-patrao. Acesso em 13/05/20.

${ }^{14}$ Sobre a obsessão por performances, Cf. VIANA, Márcio Túlio; VIANA, Anamaria Fernandes. O juiz, o operário e o bailarino: relações entre o palco, a fábrica e a sala de audiências. Belo Horizonte: RTM, 2016.

${ }^{15}$ THOMPSON, E. P. Costumes em comum: estudos sobre a cultura popular tradicional. São Paulo: Companhia das Letras, 1998.
}

Revista de Direito Brasileira | Florianópolis, SC | v. 26 | n. 10 | p. 311-324 | Mai./Ago. 2020 
Mas o que há de novo na rua - desde o fim da II Grande Guerra - é que ela vai sendo usada, cada vez mais, não apenas como lugar para o protesto ou o festejo, o abraço ou o adeus, a paz ou a rebeldia, mas como espaço original de criação, exposição e participação coletiva; uma espécie de estúdio aberto, que pode também ter algo de museu, teatro ou palco, mas cujos assistentes se tornam às vezes protagonistas.

Autores como Hanru ${ }^{16}$ lembram que as primeiras experiências nesse sentido - as dos chamados "situacionistas" - usaram a rua para contestar a sociedade de consumo, ou do "espetáculo" ${ }^{17}$; ela se tornou assim um campo de ação ideal para a transgressão, a provocação, o impacto: "os artistas encorajavam o público a compartilhar do seu entusiasmo em fazer alguma coisa de inusitada, de aventureira e arriscada, e talvez também emancipatória" ${ }^{18}$.

Irromperam então as mais variadas práticas. No fim dos anos 60 , em sua performance, o artista Vito Acconci passou um mês inteiro seguindo passantes ao acaso; dez anos depois, Hsieh Tehcing vagou por um ano pelas esquinas, recusando-se a entrar em qualquer lugar fechado; mais ou menos na mesma época, David Hammons estendia um tapete numa avenida nova-iorquina para vender flocos de neve. Outros artistas ou militantes políticos se puseram a bloquear o trânsito, pintar paredes, distribuir abraços, cantar ou dançar, declamar poemas, seduzir ou provocar os transeuntes.

Assim, a rua passava a ser vista como um espaço privilegiado não só para representar o mundo em que vivemos, mas para denunciar os seus paradoxos, os seus absurdos, e fantasiar utopias - mesmo sem teorizações por detrás:

As forças criativas - artistas, arquitetos, ativistas, etc - agiam como guerrilheiros urbanos e construíam barricadas visíveis e invisíveis, permanentes ou efêmeras, para resistir e destruir as estruturas materiais impostas pelo mundo da política e do poder do moderno planejamento urbano (...) Procuram colocar em prova o grau de tolerância do público "médio" e suscitar reflexões e discussões sobre o que deveria ser uma boa vida cívica. ${ }^{19}$

Essa revolução singular continua, e parece estar crescendo. Em inúmeros sentidos - até em nossa busca crescente pelos parques, pelas praças, numa tendência não de todo inversa à dos shoppings centers ${ }^{20}$ - a rua tende a assumir um protagonismo cada vez maior, como se vê, em nosso país, até mesmo nas últimas edições dos carnavais; e também em vários aspectos se exibe como metáfora da pós modernidade.

Por fim, se desde sempre ela traz elementos tanto da cidade formal (carros, prédios, lojas, bancos) como da cidade informal (camelôs, mendigos, cortiços, passantes em geral), consegue fundir, em alguma medida, os dois espaços - e não apenas nos carnavais. É o que se vê, por exemplo, na Praça (ou "Praia") da Estação ou no Viaduto Santa Tereza, ambos em Belo Horizonte, onde pessoas do morro convivem com segmentos da classe média (sobretudo jovens e intelectuais), ainda que essa mistura esteja apenas começando.

$\mathrm{Na}$ verdade, para um universo crescente de pessoas, a casa pode se tornar paradoxalmente - a própria rua. É ali que elas dormem, conversam, brincam com seus cachorros e guardam suas pequenas coisas. Como no filme "Cinema Paradiso", de Giuseppe Tornatore, pode

\footnotetext{
${ }^{16}$ HANRU, Hou. La stradadove si creail mondo. In: HANRU, Hou (coord.) La stradadove si creail mondo. Roma: Quodlibet-MaXXI, p. 12-40, 2018,

${ }^{17}$ DEBORD, Guy. La Société du spectacle. Paris: Gallimard, 1993.

${ }^{18}$ HANRU, ibid., p. 29.

${ }^{19}$ Idem, p.30.

${ }^{20}$ Nas pessoas que passeiam pelos corredores dos shoppings talvez se possa ver também a necessidade de ir ao encontro da verdadeira rua, embora nesse caso pervertida ou contaminada tanto pela obsessão do consumo como pela busca de segurança, diante dos medos que a cidade de hoje transmite.
}

Revista de Direito Brasileira | Florianópolis, SC | v. 26 | n. 10 | p. 311-324 | Mai./Ago. 2020 
ser que elejam até uma praça inteira como sua... No entanto, nessa casa diferente, os moradores costumam ser confundidos com o lixo das ruas.

\subsection{0 novo personagem da rua}

Como qualquer outro personagem das ruas, o coronavírus chega sem aviso; é também invisível, imprevisível e - se não nos protegemos bem - pode nos ser fatal.

Ele atinge especialmente quem está na rua - seja porque precisa lutar dia após dia pela sobrevivência, sem qualquer fundo de reserva, seja porque o seu casebre não é tão diferente da rua, ou seja, enfim, porque é ali mesmo que ele dorme, sob as marquises das lojas ou debaixo dos viadutos. Mesmo para quem tem casa, a rua pode se tornar a opção única, o último recurso para enfrentar o vírus - embora seja ali, também, a casa do vírus.

Seja como for, e embora, em si mesmo, não apresente traços positivos, é possível imaginar que o coronavirus vá produzir - ou já esteja produzindo - efeitos interessantes.

Segundo leituras otimistas, por exemplo, ele seria capaz de pôr em crise o modelo neoliberal ${ }^{21}$, reforçar o Estado $\mathrm{Nação}^{22}$, induzir novas políticas públicas ${ }^{23}$ ou criar novas perspectivas para o urbanismo ${ }^{24}$. No campo subjetivo, já estaria nos ensinando a sermos mais solidários, a consumir de forma mais responsável, ${ }^{25}$ a mudar para melhor a nossa relação com a Natureza, a potencializar o nosso espírito criativo, com formas de protesto inovadoras ${ }^{26}$ e até a nos vestirmos de forma mais simples e confortável ${ }^{27}$.

Em sentido inverso, no entanto, há os que apostam que a ameaça de novas pandemias irá permitir que o Estado Nação, seguindo o modelo chinês, produza mais vigilância sobre a cidade, as ruas e as pessoas, exacerbando o seu biopoder ${ }^{28}$; e, no campo do Direito do Trabalho, sirva de justificativa para que se intensifique o processo de destruição que há várias décadas o golpeia.

É possível, também, que o controle aumente não só em termos sanitários, mas em forma de higienização social, de eugenia. Estará então aberta a caça aos imigrantes ${ }^{29}$, aos sindicatos mais agressivos e aos militantes de esquerda em geral - riscos ainda maiores em governos como o nosso, marcados pela censura, pelo autoritarismo, pela discriminação e pela apologia da violência.

Tentando reunir algumas peças desse jogo de xadrez, parece razoável supor que a nova crise, sucessiva ao vírus, realmente sirva de pretexto para que a relação de forças entre capital e

${ }^{21}$ HAN, Byung-Chul. O coronavírus de hoje e o mundo de amanhã. El Pais. Madrid, 20/03/20, Disponível em: https://brasil.elpais.com/ideas/2020-03-22/o-coronavirus-de-hoje-e-o-mundo-de-amanha-segundo-o-filosofo-byungchul-han.html. Acesso em 12/05/20.

${ }^{22}$ IGNATIEFF, Michael. La seguridade del Estado frente a una menaza global. El País. El futuro después del coronavirus. Disponível em: https://elpais.com/especiales/2020/coronavirus-covid-19/predicciones. Acesso em $12 / 05 / 20$.

${ }^{23}$ Idem.

${ }^{24}$ SENNET, Richard. Hacia ciudades de 15 minutos. El País. El futuro después del coronavirus. Disponível em: https:/elpais.com/especiales/2020/coronavirus-covid-19/predicciones/hacia-ciudades-de-15-minutos/. Acesso em $12 / 05 / 20$.

${ }^{25}$ CAPARRÓS, Martin. O coronavirus de hoje e o mundo de amanhã. El País. Madrid, 20/03/20, Disponível em: https://elpais.com/especiales/2020/coronavirus-covid-19/predicciones/el-trabalenguas-del-hambre/. Acceso em: $12 / 05 / 20$.

${ }^{26}$ DELLA PORTA, Donatella. Protestas innovadoras. El País. El futuro después del coronavirus. Disponível em: https://elpais.com/especiales/2020/coronavirus-covid-19/predicciones/protestas-innovadoras/ Acesso em 12/05/20.

27 VALERIE, Steele. La victoria de laropa informal. El País. El futuro después del coronavirus. Disponível em: https://elpais.com/especiales/2020/coronavirus-covid-19/predicciones. Acesso em 12/05/20.

${ }^{28}$ FOUCAULT, Michel. Vigiar e punir: história da violência nas prisões. Petrópolis: Vozes, 2002.

${ }^{29}$ Cf. NAIM, Moisés. Conflictos por lasmigraciones. El País. El futuro después del coronavirus. Disponíveis em: https://elpais.com/especiales/2020/coronavirus-covid-19/predicciones/conflictos-por-las-migraciones/. Acesso em 12/05/20.; BENHABIB, Seyla. El control será más estricto.In: El País. El futuro después del coronavirus. Disponíveis em https://elpais.com/especiales/2020/coronavirus-covid-19/predicciones/el-control-sera-mas-estricto/. Acesso em $12 / 05 / 20$.

Revista de Direito Brasileira | Florianópolis, SC | v. 26 | n. 10 | p. 311-324 | Mai./Ago. 2020 
trabalho se desequilibre ainda mais. Aliás, com a perspectiva de um futuro ameaçador, a crise pode começar a ser vista como perene ${ }^{30}$; e nesse caso servirá de forma ainda melhor para acentuar as diferenças entre as classes sociais.

Não custa observar que até a razão puramente econômica exige uma guinada de 180 graus nos rumos do sistema capitalista. Um estudo publicado na Revista Science mostra, por exemplo, que "o custo para preservar o ambiente no Planeta seria de 22 bilhões de dólares, um valor considerado elevado, mas ainda menor do que os 2,6 trilhões de dólares que já foram perdidos no combate à Covid-19" 31 .

Se a hipótese mais pessimista se confirmar, o sistema poderá estar aprofundando as suas contradições internas, até mesmo em razão da plasticidade ${ }^{32}$ que lhe é inerente. E não se sabe o que virá depois. Na verdade, as próprias epidemias e tragédias climáticas - talvez não imaginadas por Marx, pelo menos nessa dimensão - poderão torná-lo inviável e forçar a sua superação.

Nessa perspectiva mais interessante, talvez os movimentos sociais consigam recuperar suas forças, e possa acontecer o que Ricardo Antunes chama de "nova rebelião social" - repetindo as que vimos nos anos 2012/2013, em várias partes do mundo ${ }^{33}$.

Também nesse sentido, não custa notar que um grande contingente de trabalhadores simples, subvalorizados, e que se viam quase à margem do respeito social, têm conquistado algum reconhecimento, aqui ou ali, por parte de pessoas que sequer os enxergavam. É o caso dos entregadores de encomendas, dos lixeiros, das "diaristas" de casa de família e de um vasto contingente de pequenos autônomos. ${ }^{34}$

Naturalmente, isso não tem impedido que sejam explorados por seus empregadores - e até mais do que antes. Pesquisas recentes mostram, por exemplo, que o salário dos motoboys que entregam mercadorias está diminuindo, enquanto as horas de trabalho aumentam. ${ }^{35}$ A explicação estaria simplesmente na lei da oferta e procura.

\subsection{Rua e Direito}

Veja-se o modelo tradicional de greve. Os grevistas usam a própria racionalidade da fábrica como instrumento de luta ${ }^{36}$. Mas as próprias paredes da fábrica têm limitado, simbolicamente, as suas aspirações e as suas conquistas. Da mesma forma, ou pela mesma razão, os protagonistas da greve têm sido os trabalhadores formais - os mesmos que, no a dia da fábrica, deixam ali o seu suor.

Hoje, de certa forma, a fábrica se desmancha - e se mexe. E em seus movimentos despeja multidões na rua. Mesmo os que não estão exatamente na rua são personagens $s$ fluidos, heterogêneos, e mudam - eles próprios - tanto de lugar, que é como se nela estivessem.

Assim como as pessoas da rua, as normas de proteção - antes, elas próprias protegidas pelas quatro paredes da casa - transitam sem rumo em várias direções, encontrando-se ou

\footnotetext{
${ }^{30}$ SANTOS, Boaventura Sousa. Vírus: tudo o que é sólido desmancha no ar. In: TOSTES, Anjuli; MELO FILHO, Hugo. Quarentena. Marilia: Projeto Editorial Práxis, 2010, p. 45.

${ }^{31}$ Estudo mostra que investir na redução do desmatamento e do tráfico de animais previne pandemias. In: BizNews/Br. Disponível em:https://www.biznews.com.br/estudo-mostra-que-investir-na-reducao-do-desmatamento-e-do-traficode-animais-previne-pandemias/ Acesso em 29/07/20.

${ }^{32}$ LATOUR, Bruno. La plasticidad del orden mundial. El País. El futuro después del coronavirus. Disponível em: https://elpais.com/especiales/2020/coronavirus-covid-19/predicciones/la-plasticidad-del-orden-mundial/. Acesso em $12 / 05 / 20$.

${ }^{33}$ ANTUNES, Ricardo. O vilipêndio do coronavirus e o imperativo de reinventar. In: TOSTES, Anjuli; MELO FILHO, Hugo. Quarentena. Marilia: Projeto EditorialPraxis, 2010, p. 181.

${ }^{34}$ A propósito, Cf. SANDEL, Michael. Hacia una politica del bien común. El País. El futuro después del coronavirus. Disponível em: https://elpais.com/especiales/2020/coronavirus-covid-19/predicciones. Acesso em 12/05/20.

35 DUVIVIER, Gregório. Greg News Delivery, edição de 17/04/20. Disponível em: https://www.youtube.com/watch?v=v3B9w6wWNQA. Acesso em 20/07/20.

${ }^{36}$ MARONI, Amneris. A estratégia da recusa. São Paulo: Brasiliense, 1982, passim
}

Revista de Direito Brasileira | Florianópolis, SC | v. 26 | n. 10 | p. 311-324 | Mai./Ago. 2020 
defrontando-se nas esquinas, embora perdendo força a cada passo. As próprias solidariedades, quando existem, tendem a ser breves, casuais, sem compromissos - à semelhança das que vemos na rua quando um velho tropeça e cai, ou um mendigo nos estende as mãos.

Paradoxalmente, parece-nos que se há alguma esperança, no futuro, para o Direito do Trabalho, é bem possível que ela também esteja nas ruas. E isso significa que ele terá de se mesclar com os mais diversos segmentos da sociedade - sobretudo as chamadas minorias - , ainda que de forma inconstante, imprevisível, sem planos a longo prazo. Em outras palavras, será a reunião de fragmentos - mais do que a soma de vozes iguais - a principal força popular que terá de exigir mais dignidade para o trabalhador. Ou, se preferirmos dizer assim, será a substituição do coletivo pelo difuso.

A propósito, não custa notar que as misturas são também um elemento presente em nosso tempo, como se vê nas escolas - com o ensino multidisciplinar -, nas modas, nos modos, nos cardápios dos restaurantes e especialmente nas artes - que nos oferecem a pintura com foto, o samba com rock, a salsa com funk ou mesmo os automóveis esportivos dos anos 50 ou 60 equipados com motor turbinado.

Trocando em miúdos, essa solução implicaria, em síntese, aproveitar os elementos positivos dos novos tempos, já que eles também existem, e não são poucos; e tentar banhá-los com a essência que o passado nos legou.

Essa essência é a proteção aos oprimidos. Apesar de todas as transformações, e mesmo em tempos de liquidez ou de "pós verdade", ela não deve jamais se perder, pois expressa a nossa própria humanidade. Negá-la seria o mesmo que afirmar o desejo de nos tornarmos lobos na planície, ou talvez numa "Terra plana" 37.

Veja-se que até os novos movimentos sociais - ou muitos deles - têm procurado essa espécie de terceira via, compondo-se com os novos tempos, ou mais exatamente com os elementos interessantes que eles nos trazem. O melhor exemplo são as ocupações. Ao invés de sonhar primeiro para fazer depois, os novos militantes, ou ocupantes, deixam-se afetar pelo presente, com todas as suas inconstâncias, e a partir daí vão realizando as suas práticas, em busca de uma terra ou de um lar.

É como se, na falta de um grande futuro confiável, tentassem antecipá-lo - em dose menor, e de forma casuística - para o presente. E sempre aprendendo com a prática, no dia a dia, recriando táticas e estratégias, embora sem perder aquela essência.

Outros exemplos são a busca por mais democracia direta, por relações mais igualitárias, com a participação em inúmeros níveis - dos programas de TV ao orçamento participativo. Em todas essas dimensões, os movimentos sociais se nutrem de elementos pós-modernos; e tentam resgatar, em suas práticas, a etimologia da palavra "companheiro" - do Latim cumpanis, que expressava o costume de "repartir o pão"38.

\section{CONCLUSÕES}

Com a exaustão do modelo casa, e a provável chegada de novas calamidades, as desigualdades irão provavelmente aumentar. No modelo rua, os riscos tendem a ser cada vez maiores, assim como as lutas pela sobrevivência - não só de cada um, mas do próprio Direito do Trabalho.

Paradoxalmente, se há alguma esperança, é provável que ela também esteja nas ruas. Mas para isso será necessária à força de pressão dos mais variados segmentos sociais, ainda que de forma fluida, imprevisível, pragmática, como convém aos novos tempos.

Isso significa, também, que o Direito do Trabalho não será construído apenas - ou tanto por grupos de pessoas homogêneas, ligadas por condições semelhantes de trabalho. Será produto

\footnotetext{
${ }^{37}$ Teoria esposada por certos apoiadores da atual direita radical brasileira.
}

${ }^{38}$ BRANDY, Daniel. Motamorphoses. Paris: Casterman, 1986, p. 36.

Revista de Direito Brasileira | Florianópolis, SC | v. 26 | n. 10 | p. 311-324 | Mai./Ago. 2020 
de gentes dos mais diferentes aspectos, profissões, culturas, mas todas elas animadas pelo fogo - o mesmo fogo que animava os corpos e corações nas casas da cidade antiga.

Será então a reunião desses fragmentos - mais do que a soma de vozes iguais, como as do sindicato e as de suas greves - a principal força popular que irá exigir e poderá obter melhores condições de vida e dignidade.

Dito de outro modo, a construção que se espera possível para o Direito do Trabalho não será semelhante à que lhe deu origem - ou à que está presente em nossos projetos de casa. Será feita a cada dia, palmo a palmo, sem pausa, sem fôlego, sem descanso, como nas históricas barricadas do passado, e também sem desalento.

Provavelmente, assim como acontece com as pessoas da rua, esse processo poderá encontrar, em cada esquina, em cada dia, tanto uma surpresa feliz quanto uma terrível ameaça. E terá talvez idas e vindas, e confrontos constantes. E o Direito do Trabalho que surgir daí só se sustentará se conseguir gritar escandalosamente as suas vontades e verdades, e conseguir impor a sua presença, como também vemos acontecer tantas vezes nas ruas.

Em certo sentido, o símbolo - ou a "metáfora humana" - desse novo Direito do Trabalho já não será tanto ou apenas o operário de fábrica, nem o empregado de escritório, que contam com alguma garantia, mesmo que às vezes pequena, de que no fim do mês poderão pagar as suas contas; será antes o ambulante, o malabarista, o comedor de fogo, o vendedor de droga, o pequeno contrabandista, o homem placa ${ }^{39}$, o gritador, ${ }^{40}$ a mulher que vende doces, o menino que nos oferece cigarros e - de modo especial - o entregador de encomendas, o motoboy, que hoje desliza por nossas vidas como faz entre os carros no trânsito. Pois eles realmente lutam, a cada dia, ou a cada hora, para comer no dia ou na hora seguinte.

Entre eles estará também outro personagem que ganhou destaque na pandemia: o teletrabalhador. Mesmo estando em casa, ele trabalha num espaço - a Internet - com elementos próprios da rua. E o seu universo- já expandido - tende a crescer cada vez mais, pois a fase da pandemia ensinou às empresas, definitivamente, que é mais barato e produtivo explorar o trabalhador em seu próprio ambiente. Afinal, ao contrário dos tempos pré-capitalistas, já não é difícil controlar à distância; além dos próprios meios tecnológicos, a empresa pode utilizar, com muito mais eficiência, a própria alma do trabalhador.

Construído da mesma forma que esses sujeitos, o Direito do Trabalho terá de ser também assim, ou pelo menos em grande parte assim. Um Direito flexível - no sentido de cambiante - mas mantendo o mesmo rigor em sua luta histórica. Um Direito - ainda que troque de nome - capaz de abranger não apenas trabalhadores subordinados, como hoje acontece, mas todos os que, vivendo do trabalho, são explorados pelo sistema econômico, ainda que de forma menos direta e visível.

Para o sindicato, isso significa, talvez - dentre tantas outras medidas - ver-se mais como coalizão do que como organização sólida; cobrar menos compromissos e aceitar mais adesões efêmeras; e reconstruir suas práticas em termos líquidos e múltiplos, inclusive no sentido de se abrir para fora de si mesmo.

Antes habituado à greve - com o seu planejamento, as suas táticas, os seus líderes, e os seus militantes tão iguais, como soldados de um regimento - o sindicato terá de ir se habituando às manifestações plurais, rebeldes, multicoloridas, menos controláveis e previsíveis. Ao ganhar as ruas - nos sentidos real e metafórico - suas pautas serão talvez mais efêmeras, circunstanciais, mas é possível que façam germinar aspirações maiores, radicais, por um novo modelo de mundo e de vida.

Por tudo isso, seria útil, para ele, receber lições daqueles novos movimentos sociais, que vêm trocando o vertical pelo horizontal, construindo suas metas a partir das próprias práticas e deste modo inserindo - de forma quase oposta à dos velhos tempos - pequenas, mas profundas

\footnotetext{
${ }^{39}$ É o título que com frequência se dá, em algumas capitais, aos que oferecem aos transeuntes a possibilidade de vender suas peças de ouro.

${ }^{40}$ É o nome que se costuma dar aos que vendem celulares nas ruas de cidades como Belo Horizonte.
} Revista de Direito Brasileira | Florianópolis, SC | v. 26 | n. 10 | p. 311-324 | Mai./Ago. 2020 
contradições no sistema. Mas deverá também juntar-se a eles, como começa a ensaiar, mesmo porque suas razões e objetivos, em última análise, são comuns.

E seria útil, ainda, utilizar de forma mais eficaz as redes sociais e outros elementos da tecnologia; tentar reconstruir, em outras bases, algo das solidariedades perdidas, talvez mesclando o interesse coletivo com o individual; e se habituar, humildemente, a um exercício constante de autocrítica, para mudar sempre, na mesma velocidade com que mudam os produtos, as ideias e as práticas do nosso tempo.

É importante notar que - para além das ocupações - o indivíduo do nosso tempo vem encontrando ou inventando nas próprias ruas elementos de resistência, como acontece ainda uma vez no campo das artes, com os grafites, as pichações, as práticas de flashmob, as danças no metrô, os teatros nas praças, as poesias do slam, os concertos nos parques, os malabaristas de esquina ou as instalações que param, às vezes, o próprio trânsito, para anunciar novas verdades, mesmo fluidas. E uma participação mais intensa desses sujeitos na vida do Direito significará, naturalmente, um Direito um pouco menos escravo das classes dominantes e um pouco mais comprometido com a justiça social.

$\mathrm{Na}$ verdade, o próprio sujeito parece estar se reinventando, e não necessariamente de forma pior que no passado. Como sujeito rua, talvez esteja mais vulnerável, oscilante, correndo mais riscos; e têm gerado reações opostas, algumas violentas, como a dos sujeitos arma ${ }^{41}$; mas o importante é que diante dele será cada vez mais difícil discriminar, assediar ou ignorar impunemente as distorções de nossa sociedade ou do próprio legislador ${ }^{42}$.

O próprio trabalhador formal, que tem sido descrito como mais passivo - vítima de uma "captura de subjetividade" 43 - pode estar sendo inoculado também com um elemento ativo, que hoje serve ao sistema, mas amanhã talvez o dessirva. Afinal, se o capital tenta fazer com que ele reaja como capitalista - performático, obcecado com a concorrência, disposto a tudo para vencer até que ponto conseguirá controla-lo no futuro, se ele voltar a se perceber trabalhador?

\section{REFERÊNCIAS}

ALMEIDA, Cleber Lúcio de. Por um direito do trabalho de segunda geração: trabalhador integral e direito do trabalho integral. Disponível em: http://as1.trt3.jus.br/bdtrt3/bitstream/handle/11103/27282/Por\%20um\%20Direito\%20do\%20Trabalho\%20\%20cleber.pdf?sequence=1\&isAllowed=y. Acesso em 12/05/20.

ALVES, Giovanni. Trabalho e subjetividade: o espírito do toyotismo na era do capital manipulatório. São Paulo: Boitempo, 2011.

ANTUNES, Ricardo. O vilipêndio do coronavirus e o imperativo de reinventar. In: TOSTES, Anjuli; MELO FILHO, Hugo. Quarentena. Marilia: Projeto EditorialPraxis, 2010.

BAUMAN, Zigmundt. A modernidade líquida. São Paulo: Zahar, 2014.

BENHABIB, Seyla. El control será más estricto.In: El País. El futuro después del coronavirus. Disponíveis em https://elpais.com/especiales/2020/coronavirus-covid-19/predicciones/el-control-seramas-estricto/. Acesso em 12/05/20.

\footnotetext{
${ }^{41}$ Embora em contexto um tanto diferente, ver Cf. MERLEAU-PONTY, Maurice. Fenomenologia da percepção. São Paulo: Martins Fontes, 1994, p.29.

42 Sobre o jogo sujo que deu origem à recente reforma trabalhista no Brasil veja-se: MAIOR, Jorge Luiz Souto. A quem interessa esta reforma trabalhista? Disponível em: https://www.jorgesoutomaior.com/blog/a-quem-interessaessa-reforma-trabalhista Acesso em 12/05/18.

${ }^{43}$ Cf. ALVES, Giovanni. Trabalho e subjetividade: o espírito do toyotismo na era do capitalismo manipulatório. São Paulo: Boitempo, 2011.
}

Revista de Direito Brasileira | Florianópolis, SC | v. 26 | n. 10 | p. 311-324 | Mai./Ago. 2020 
BRANDY, Daniel. Motamorphoses. Paris: Casterman, 1986.

CAPARRÓS, Martin. O coronavirus de hoje e o mundo de amanhã. El País. Madrid, 20/03/20, Disponível em: https://brasil.elpais.com/ideas/2020-03-22/o-coronavirus-de-hoje-e-o-mundo-deamanha-segundo-o-filosofo-byung-chul-han.html. Acesso em: 12/05/20.

COULANGES, Fustel de. A cidade antiga. São Paulo: Editora das Américas, 2006.

DEBORD, Guy. La Sociétéduspectacle. Paris: Gallimard, 1993.

DELLA PORTA, Donatella. Protestas innovadoras. El País. El futuro despuésdelcoronavirus. Disponível em: https://elpais.com/especiales/2020/coronavirus-covid-19/predicciones. Acesso em $12 / 05 / 20$.

DOS SANTOS, Geraldo Alves dos. A pedagogia da ferramenta: estratégias de produção e formalização de saberes tácitos criados pelos ferramenteiros de uma indústria metalúrgica (dissertação de mestrado). Belo Horizonte: UFMG, 2004.

DUVIVIER, Gregório. Greg News Delivery, edição de 17/04/20. Disponível em: https://www.youtube.com/watch?v=v3B9w6wWNQA. Acesso em 20/07/20.

FEDERICI, Silvia. Calibã e a bruxa: mulheres, corpo e acumulação primitiva. São Paulo: Elefante, 2017.

FOUCAULT, Michel. Vigiar e punir: história da violência nas prisões. Petrópolis: Vozes, 2002.

FOX-SKELLY, Jasmin. There are diseases hidden in ice, and they are waking up. BBC, 04 may 2017. Disponível em:

http://www.bbc.com/earth/story/20170504-there-are-diseases-hidden-in-ice-and-they-arewaking-up.Acesso em 20/09/2020.

HAN, Byung-Chul. O coronavírus de hoje e o mundo de amanhã. El Pais. Madrid, 20/03/20, Disponível em: https://brasil.elpais.com/ideas/2020-03-22/o-coronavirus-de-hoje-e-o-mundo-deamanha-segundo-o-filosofo-byung-chul-han.html. Acesso em 12/05/20.

HANRU, Hou. La stradadove si crea il mondo. In: HANRU, Hou (coord.) La stradadove si creail mondo. Roma: Quodlibet - MaXXI, 2018.

HOBSBAWM, Eric. Era dos extremos. São Paulo: Companhia das Letras, 1995.

IGNATIEFF, Michael. La seguridaddel Estado frente a una menaza global. El País. El futuro despuésdelcoronavirus. Disponível em: https://elpais.com/especiales/2020/coronavirus-covid19/predicciones. Acesso em 12/05/20.

LA CUEVA, Mario. El Nuevo Derecho Mexicano del Trabajo, tomo I. México: Porrua, 1956.

LATOUR, Bruno. La plasticidade del orden mundial. El País. El futuro despuésdelcoronavirus. Disponível em: https://elpais.com/especiales/2020/coronavirus-covid-19/predicciones. Acesso em $12 / 05 / 20$. 
LIMA, Maria Elizabeth Antunes. Os equívocos da excelência. Petrópolis: Vozes, 1996.

MAIOR, Jorge Luiz Souto. A quem interessa esta reforma trabalhista? Disponível em: https://www.jorgesoutomaior.com/blog/a-quem-interessa-essa-reforma-trabalhista. Acesso em $12 / 05 / 18$.

MARONI, Amneris. A estratégia da recusa. São Paulo: Brasiliense, 1982,

MERLEAU-PONTY, Maurice. Fenomenologia da percepção. São Paulo: Martins Fontes, 1994.

MONOD, Jacques. O acaso e a necessidade. Petrópolis: Vozes, 1976.

MORENO, Jose Maria M. Habrá más epidemias y serán más peligrosas. In: El País. El futuro despuésdelcoronavirus. Disponível em: https://elpais.com/especiales/2020/coronavirus-covid19/predicciones. Acesso em 12/05/20.

NAIM, Moisés. Conflictos por lasmigraciones. El País. El futuro después del coronavirus. Disponíveis em: https://elpais.com/especiales/2020/coronavirus-covid19/predicciones/conflictos-por-las-migraciones/. Acesso em 12/05/20.

NORONHA, Elaine Nassif. Conciliação judicial e indisponibilidade de direitos: paradoxos da "justiça menor" no processo civil e trabalhista. São Paulo: LTr, 2005.

SANDEL, Michael. Hacia una política del bien común. El País. El futuro después del coronavirus. Disponível em: https://elpais.com/especiales/2020/coronavirus-covid19/predicciones. Acesso em 12/05/20.

SANTOS, Boaventura Sousa. Vírus: tudo o que é sólido desmancha no ar. In: TOSTES, Anjuli; MELO FILHO, Hugo. Quarentena. Marilia: Projeto EditorialPraxis, 2010.

SENNET, Richard. Hacia ciudades de 15 minutos. El País. El futuro después del coronavirus. Disponível em: https://elpais.com/especiales/2020/coronavirus-covid-19/predicciones. Acesso em $12 / 05 / 20$.

TEODORO, Maria Cecilia Máximo. A síndrome de patrão. Mgalhas, 4 de maio de 2017. Disponível em: https://www.migalhas.com.br/depeso/258217/a-sindrome-de-patrao. Acesso em $\underline{13 / 05 / 20}$.

THOMPSON, E. P. Costumes em comum: estudos sobre a cultura popular tradicional. São Paulo: Companhia das Letras, 1998.

VALERIE, Steele. La victoria de laropa informal. El País. El futuro despuésdelcoronavirus. Disponível em: https://elpais.com/especiales/2020/coronavirus-covid-19/predicciones. Acesso em $12 / 05 / 20$.

VAZQUEZ, Adolfo Sánchez. As ideias estéticas de Marx. Rio de Janeiro: Paz e Terra, 1968.

VIANA, Márcio Túlio; VIANA, Anamaria Fernandes. O juiz, o operário e o bailarino: relações entre o palco, a fábrica e a sala de audiências. Belo Horizonte: RTM, 2016. 
VIANA, Virgílio Mauricio, professor convidado em Harvard. Palestra no Programa de Pósgraduação em Direito na PUC-Minas. Belo Horizonte, 18/03/19.

WEIL, Simone. A condição operária e outros estudos sobre a opressão. Rio de Janeiro: Paz e Terra, 1996. 